\title{
Investigation of Z-R Relationships for Monsoon Seasons over Southern Thailand
}

\author{
Sukrit Kirtsaeng ${ }^{1, a}$ and Pakdee Chantraket ${ }^{2}$ \\ ${ }^{1}$ Meteorological Development Bureau, Thai Meteorological Department, \\ Bangkok, Thailand 102602 \\ 2 Department of Royal Rain-making and Agricultural Aviation, Bangkok, Thailand 10900 \\ asukritk@hotmail.com
}

Keywords: Z-R relationship, weather radar, rainfall estimation, monsoon season, southern Thailand

\begin{abstract}
This research aimed to study the rainfall estimation with weather radar in southern Thailand. Both precipitation data from Sathing-Phra radar station, Songkhla, and hourly rainfall data from automatic tipping bucket rain gauges are of the Thai Meteorological Department (TMD) in 2012-2013. These data were used to study the relationship between radar reflectivity ( $\mathrm{Z}$ ) and intensity of the rainfall $(\mathrm{R})$ in both monsoon season. The rain-rate obtained from radar with Z-R equation was a precise rain estimate method. The calculation provided the rain-rate more accurate than original equation often used. The equation of this study was best used during the northeast monsoon which occurred in rainy season in eastern coast of the South (Thailand's Gulf). However, the result of this study should be improved to estimate rain-rate by radar for southern Thailand and, as input data, applied for applications of early warning systems.
\end{abstract}

\section{Introduction}

Remote sensing, such as weather radar and meteorological satellites, has dramatically been improved at present. It can be widely applied to various missions, for example, science, environmental engineering, natural disaster and other related fields [1-3]. One important mission on meteorology includes measurement of rainfall amount to be used for analyzing and monitoring, as well as natural disaster warnings and weather forecast. The weather radar and satellite meteorology are optionally integrated for estimating to reduce limitations of rain detection with primitive way that provide pointed data not covering remote areas, dense jungle, mountains, large lagoons and sea. It also enhances the effectiveness of early warning and weather forecasting more efficient than in the past.

The measurement system with weather radar depends on electromagnetic wave transmitting to water droplets in the air, reflecting back to the receiver, and displaying $\mathrm{Z}$ factor [4] that is correlated with the amount of rainfall (R) for reducing the discrepancy. For example, a study in the Netherlands showed the radar signal reflection that is a function of water drop size to the fourth power or to the sixth power $\left(\mathrm{X}^{4}, \mathrm{X}^{6}\right)$. Rain reflection and its amount have several relationships according to area and different high altitude levels, such as types of precipitation (cumulus, stratus), climate, topography, etc. However, in routine work, there is a standard value for operation (to achieve work performance). Using only nationwide Z-R relationship may cause rainfall estimate error [5] that is possibly due to several factors, for example, patterns of vertical reflection of precipitation directly affecting Z-R relationship, absence of rain reflection, reduction of rain/other obstruction signal, etc. The Z-R relationship is associated with precipitation drop size including the above signal reduction discussed.

Z-R relationship was performed into three ways: 1) the use of disdrometer to measure raindrop size and calibrate with rain rate, 2) comparison of signal reflection with minimum error of rain-rate and 3 ) the use of probability to determine the relation between signal reflection and rain-rate based on cumulative distribution function. 
Although Marshall and Palmer's (1948) Z-R relation is widely used, it is still studied extensively and continuously in the fields of weather radar research, rain anticipation and nowcasting model [6] This is due to the difference of topography of radar installation and the physic of rain cloud of each area. Some of previous researches are also associated with Z-R equation as shown in Table 1.

Table 1. Some of recent research related to Z-R relationship.

\begin{tabular}{cllcc}
\hline Researcher & \multicolumn{1}{c}{ Study place } & Precipitation type & a & b \\
\hline Marshall\&Palmer [7] & Wildly used globally & All types (bulk) & 200 & 1.60 \\
Rosenfeld [8] & Darwin, Australia & Tropical rain & 250 & 1.20 \\
WSR-88D [9] & South Carolina, USA & All types (bulk) & 300 & 1.40 \\
& & Summer Deep & & \\
& & Convection & & \\
Chantraket, et al. [10] & Eastern Thailand & Monsoon Rain & 201 & 1.50 \\
\hline
\end{tabular}

The returned signal from the transmitted pulse reflects rainfall intensity, for example, if the reflection is more than $23 \mathrm{dBZ}$, light rain begins. It becomes severe signal based on the growth of rain bands. However, constant ' $a$ ' varies from 0 to 500, and constant ' $b$ ' changes from 1.0 to 2.0 depending on climatic conditions and topography [11]. For Thailand, the Department of Royal Rain-making and Agricultural Aviation (2013) studied ' $a$ ' and ' $b$ ' parameters with Z-R relation by several years of radar reflection measurement. It was found that ' $b$ ' was proper for representing well $\mathrm{Z}-\mathrm{R}$ equation. That is to say, $\mathrm{b}=1.5$ [12].

This study aims to investigate the relationship between the reflection of radar and the intensity of rain comparing with Z-R relation both of this study and of previous study. The data used include rainfall estimated by weather radar, as well as hourly rain gauge from automatic weather station to find proper Z-R equation. These data are of course from Sathing-Phra radar station under Thai Meteorological Department (TMD).

\section{Data Used and Experimental Process}

Data used. Meteorological data provided both radar data from Sathing-Phra radar station and actual hourly rainfall from automatic rain gauge stations for analysis, verification and comparison in this research. All these data were observed during years 2012 to 2013 . Within $240 \mathrm{~km}$ radius of Sthing-Phra station, there are total of 164 observed rain gauge stations covering lower southern Thailand.

\section{Process of Experiment}

1. Data collection.

2. Format of Cartesian coordinate system with weather radar data.

3. Determination of cloud base altitude consistent with observed rainfall by rain gauges.

4. $Z-R$ relationship analysis with equation $Z=a R^{b}$ (when ' $a$ ' and ' $b$ ' are the parameters of the study).

5. Statistical verification of rainfall estimate from Z-R relationship.

6. Comparison of rainfall estimate of this study with previous studies from Z-R relationship.

\section{Results and Discussions}

This study was conducted by analysis of the relationship between radar reflectivity and rain intensity of Sthing-Phra radar station, as well as a comparison of rainfall estimate obtained from the weather radar with three equations: the study equation, Marshall-Palmer equation, and WSR88D equation.

Assessment of suitable altitudes of radar data product for rain estimation. In this study, the altitude levels of radar data product are selected above ground at $1.50,2.25,3.00$ and $3.75 \mathrm{~km}$, respectively. Rainfall data from automatic monitoring station are in operational radius of $160 \mathrm{~km}$ 
for investigating Z-R equation and a suitable altitude of Sathing-Phra radar station. Criteria for selecting parameter $Z$ needs all rain events that have signals consistent with actual measurement in rainy days to create $Z-R$ equation.

Evaluation of selecting appropriate altitude and Z-R relationship benefits for weather radar to observe rain with unseen data. At the similar place, the RMSE (Root Mean Square Error) is considered during the rain forecast from equations Z-R of each altitude comparing with actual rainfall as Table 3 shown.

Table 3. Assessment of weather radar data at various altitudes

\begin{tabular}{cccc}
\hline $\begin{array}{c}\text { Altitude } \\
(\mathbf{k m})\end{array}$ & Number (pair) & $\mathbf{a ~ ( b = 1 . 5 )}$ & RMSE \\
\hline 1.50 & 4887 & 140 & 6.900 \\
2.25 & 3983 & 168 & 6.277 \\
3.00 & 3593 & 158 & 6.037 \\
3.75 & 3931 & 160 & 6.118 \\
\hline
\end{tabular}

Table 3 shows lowest RMSE at 6.037. The RMSE decreases based on altitude up to $3 \mathrm{~km}$, and it then increases. This study exhibits the lowest error of radar reflection at $3 \mathrm{~km}$ above ground comparing with actual measurement. The high level is suitable for the equation to predict rain of the South. However, Chantraket (2013 and 2016) reveals the appropriate height used in Z-R equation at $1.5 \mathrm{~km}$ for Takhlee (central Thailand) [12] and $1.75 \mathrm{~km}$ for Sattahip (eastern Thailand) [10], clearly observed higher than any other radar places. This is due to the landscape of the South lying parallel to eastern seashore; therefore, the uplift of developing clouds on the windward side of the mountain is higher than other sides. As the South locates nearer the equator than any other regions, the upper edge of troposphere over this region rises up high and leads to the cloud base uplift higher than other higher latitudes.

Z-R equations suitable for rain estimation. The reflected signals, as well as verified automatic rainfall data, are selected to study during years 2012 to 2013. Experimental periods are divided into three trials as following:

1. May 2012 to October 2012 affected by southwest monsoon

2. November 2012 to February 2013 affected by northeast monsoon

3. May 2012 to February 2013 (affected by both above monsoons)

At $3 \mathrm{~km}$ above MSL, find a value (from 0 to 500) that has lowest error of RMSE where constant ' $\mathrm{b}$ ' is 1.5 [13]. Z-R relationship is analyzed as Table 4.

Table 4. Parameter ' $a$ ' indicating lowest error

\begin{tabular}{ccccc}
\hline EXP & Number (pair) & $\mathbf{a}(\mathbf{b}=\mathbf{1 . 5})$ & $\mathbf{R M S E}$ & $\mathbf{G} / \mathbf{R}$ \\
\hline 1 & 1398 & 184 & 6.2499 & 2.0530 \\
2 & 998 & 104 & 5.6569 & 1.7962 \\
3 & 2396 & 162 & 6.0849 & 2.0985 \\
\hline
\end{tabular}

In table 4, EXP 1 (southwest monsoon) has a pair number of rainfall estimate and intensity more than EXP 2 (northeast monsoon) does. 'A' was valued from 104 to 184 with error from 5.6569 to $6.2499 \mathrm{~mm} / \mathrm{hr}$. In EXP 1, equation $Z=184 \mathrm{R}^{1.5}$ gave lowest error $(\mathrm{RMSE}=6.2499 \mathrm{~mm} / \mathrm{hr}$ ) with adjustment value $G / R$ calculated 2.0530. In EXP 2, equation $Z=104 R^{1.5}$ gave lowest error $\left(\mathrm{RMSE}=5.6569 \mathrm{~mm} / \mathrm{hr}\right.$ ) with adjustment value $\mathrm{G} / \mathrm{R}$ 1.7962. In EXP 3, equation $\mathrm{Z}=162 \mathrm{R}^{1.5}$ gave lowest error $(\mathrm{RMSE}=6.0849 \mathrm{~mm} / \mathrm{hr})$ with adjustment value $\mathrm{G} / \mathrm{R} 2.0985$. 


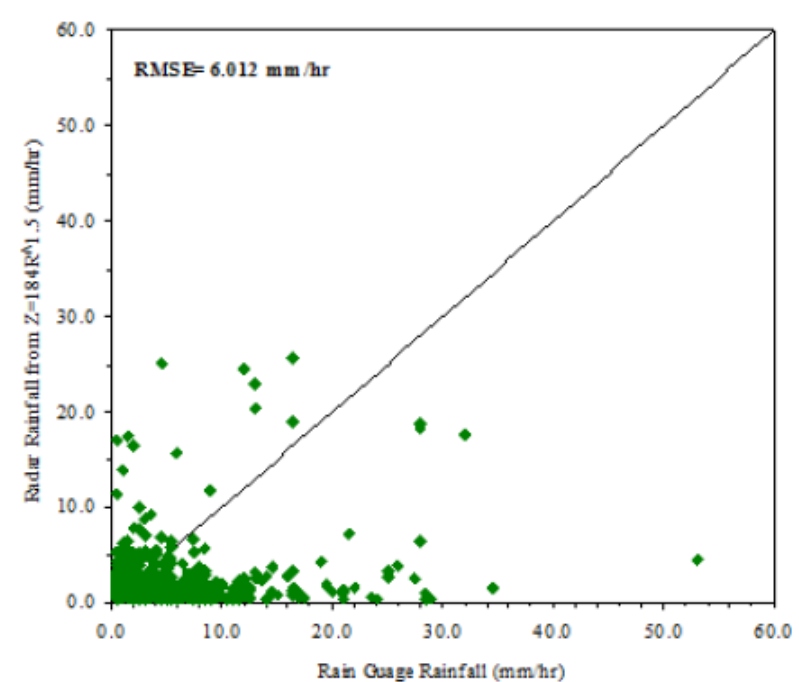

(a)

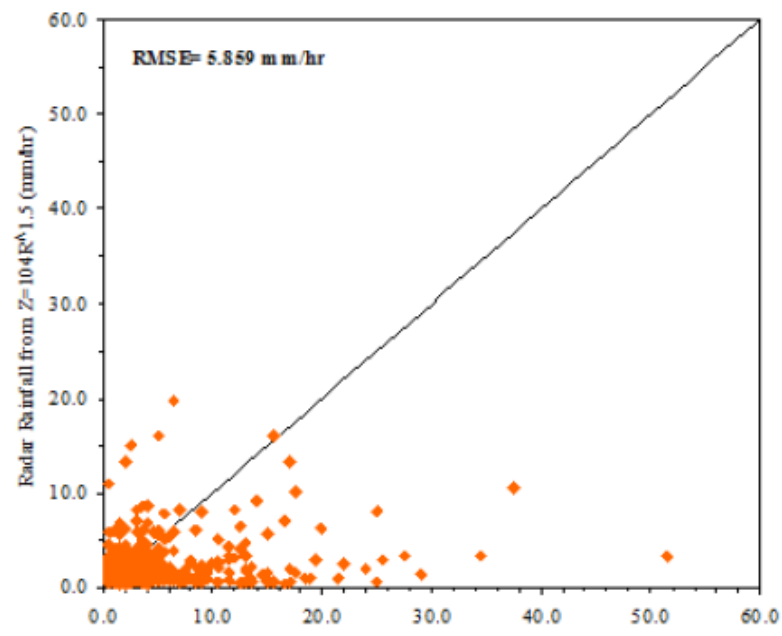

(c)

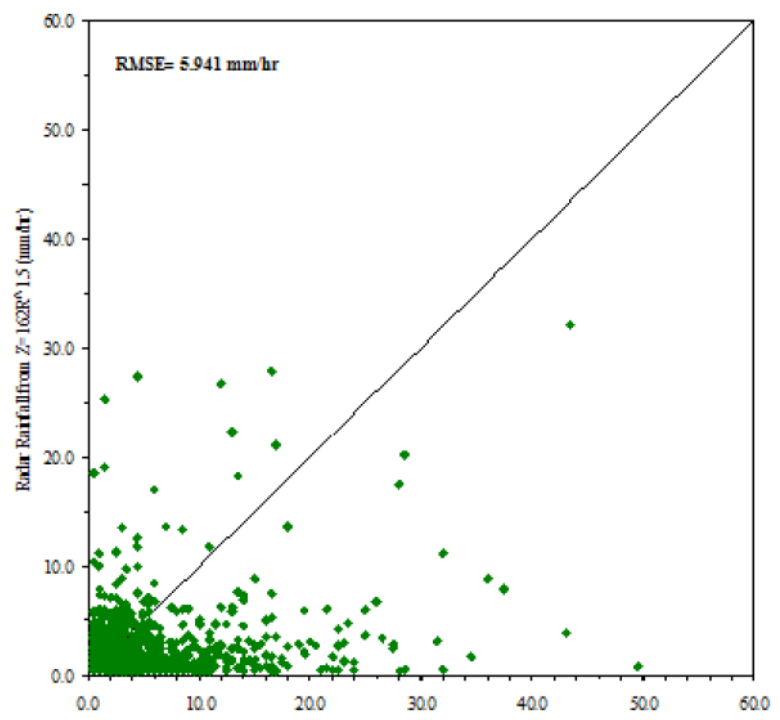

(e)

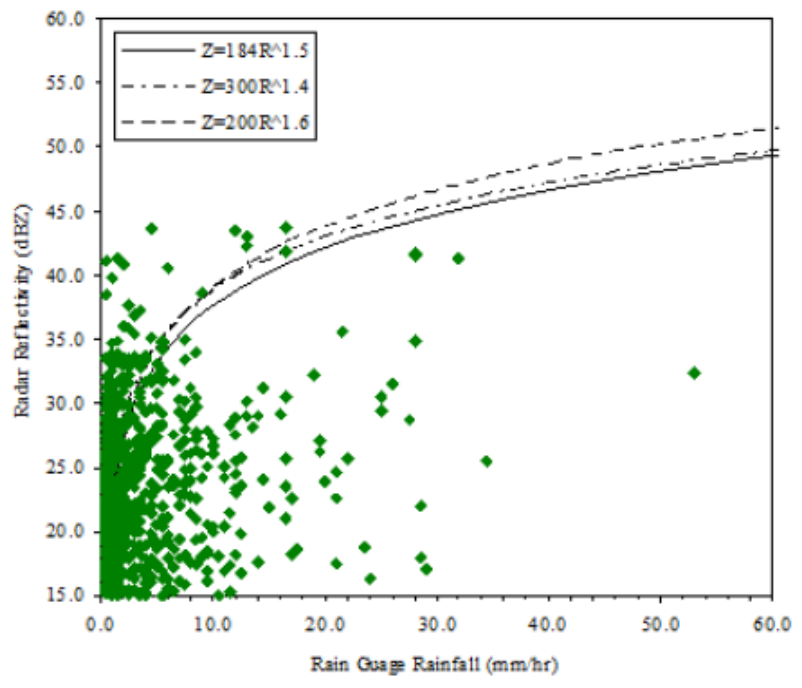

(b)

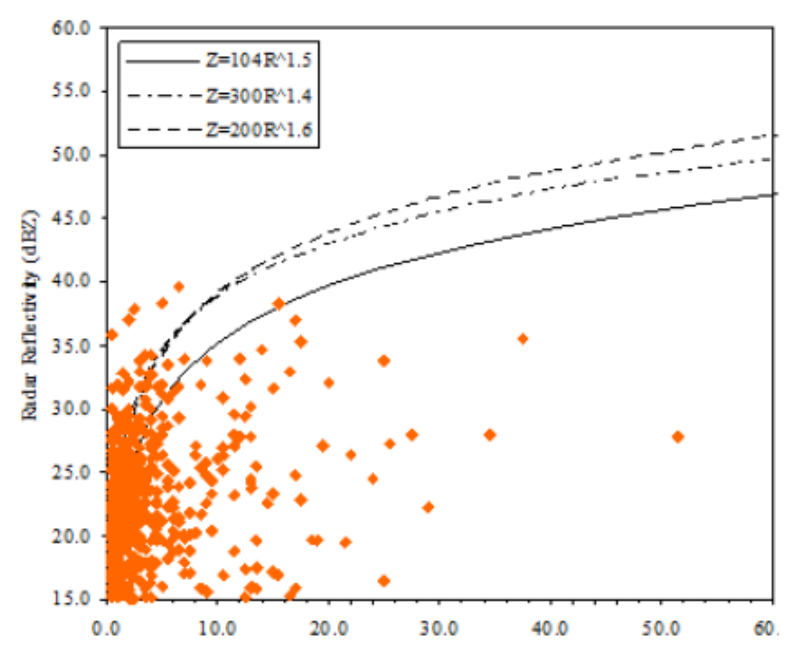

(d)

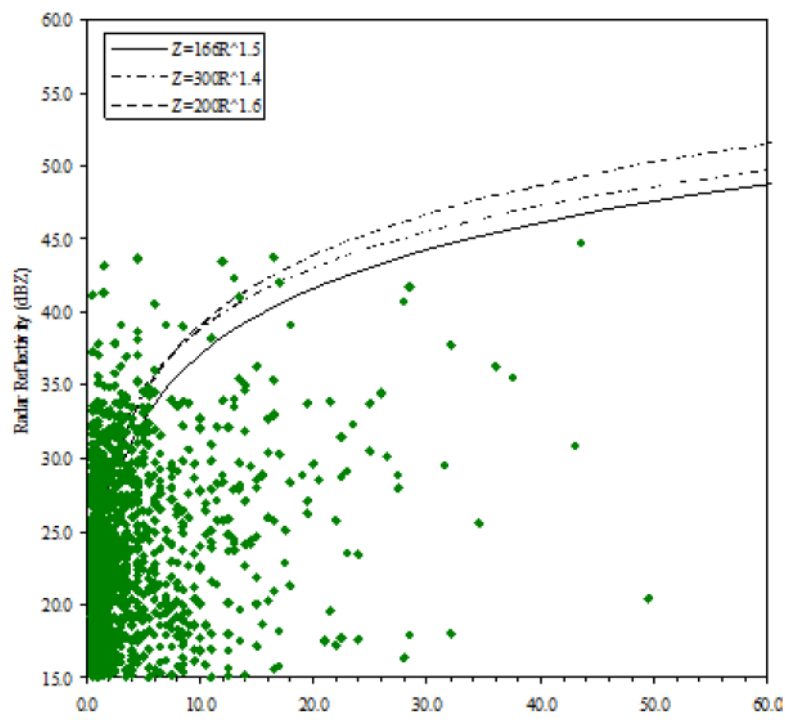

(f)

Fig.2 Test of Z-R equations (EXP 1) derived from the study with new data sets consist of (a) the relationship of rainfall rate calculated from study equations comparing with actual rain rate and (b) the comparison of radar reflection with rainfall intensity based on radar equations. EXP 2 for (c), (d) and EXP 3 for (e), (f). 
Verification of Z-R equation derived from the study with another unseen data set that was not used in modeling. The rate of precipitation was calculated and applied for predicting rain rate corresponding to actual measurement if the approximated rain rate is less than $20-30 \mathrm{~mm} / \mathrm{hr}$ as in Figure 2(a)-2(f). In case of heavy rain, measuring rain in point format gave higher value than expected spatial rainfall [2]. In comparison with actual measurement, the rain from the model was underestimated due to the above reasons. However, with the limitations of the South terrain surrounding with sea, it obstructed us to measure rain and led to estimate accuracy of the south less than other region of the country.

Comparison of rain estimate based on weather radar. Comparing radar reflection with rainrate as in figure $2(\mathrm{a}-\mathrm{f})$, the relation from 3 experiments provided estimated values lower than Marshall-Palmer's $(a=200, b=1.6)$ and WSR88D's $(a=300, b=1.4)$ equations. About accuracy of radar assessment during influence of seasonal monsoons, it displays the estimate of study equation, as well as previous equation as table 5 below.

Table 5. Error of rain anticipation with Z-R equations

\begin{tabular}{|c|c|c|c|c|c|c|c|}
\hline \multirow{2}{*}{ EXP } & \multirow{2}{*}{$\begin{array}{l}\text { Number } \\
\text { (pair) }\end{array}$} & \multicolumn{2}{|c|}{$\begin{array}{c}\text { Research } \\
(b=1.5)\end{array}$} & \multicolumn{2}{|c|}{$\begin{array}{c}\text { Marshall- } \\
\text { Palmer }\end{array}$} & \multicolumn{2}{|c|}{ WSR88D } \\
\hline & & RMSE & MAE & RMSE & MAE & RMSE & MAE \\
\hline $1(\mathrm{a}=184)$ & 698 & 6.0123 & 3.2766 & 6.0989 & 3.2002 & 6.0874 & 3.3024 \\
\hline $2(a=104)$ & 499 & 5.8587 & 3.1681 & 5.9610 & 3.2027 & 6.2133 & 3.2769 \\
\hline $3(\mathrm{a}=162)$ & 1197 & 5.9414 & 3.4997 & 5.9737 & 3.4701 & 6.0890 & 3.5719 \\
\hline
\end{tabular}

Table 5 shows EXP 1, EXP 2 and EXP 3 under the terms of the southwest monsoon, the northeast monsoon and both seasonal monsoons, respectively. In evaluation, the error of rainfall estimate was lower than Marshall-Palmer and WSR88D's equation. Of the three trials, not much difference of error range occurred. RMSE was in range from 5.8587 to $6.0123 \mathrm{~mm} / \mathrm{hr}$ while MAE was from 3.1681 to $3.4997 \mathrm{~mm} / \mathrm{hr}$. EXP 2 released lowest error, but EXP 1 gave highest.

\section{Conclusions}

This study gave us a Z-R relation between Sonkhla's radar stations and hourly precipitation data from automatic monitoring station during 2012-2013 for estimating rain with weather radar in various seasons. The reduction of equation error was carried out by the equation of Marshall-Palmer and WSR88D to make more accurate prediction. As a result, it was suitable for improving the estimate of precipitation by radar in the South of Thailand. On the other hand, in case of a large number of radar data used, it might have different Z-R relationships. And if another method is used [8], it will deliver lower error but not high accuracy in verification.

In EXP 3 (covering both seasonal monsoons), the error of rain estimate was lower than equation of EXP 1 (southwest monsoon) because a growing number of data pairs were used. Then, we considered the equation of EXP 3 for evaluation of rainfall during the southwest monsoon. The study found that the equation provided most precise estimation of the northeast monsoon.

Further study can be applied for weather watch, disaster warnings and weather prediction for southern Thailand, such as heavy rainfall warning, landslide warning, rainfall estimate models, hydrological data import format and so on.

\section{Acknowledgment}

Authors wish to acknowledge the Bureau of Meteorological Development, TMD that supported us the opportunity to do this research. The use of the weather radar observation data and rainfall observation data from TMD are thankfully acknowledged. The authors are also very grateful to Sukit Pankaew and Asadarnkdej Pokam for technical support. 


\section{References}

[1] T. Chanyatham and S. Kirtsaeng, Comparison and Analysis of Remote Sensing-Based and Ground-Based Precipitation Data over India. Chiang Mai Journal of Science, 2011, 38(4): 541-550.

[2] S. Kirtsaeng and P. Sukthawee, Comparison of rainfall pattern and statistical verification of CPS for extreme rainfall simulation on 13 April 2013. International Conference on Science and Technology, 2015, 481-488. (DOI : 10.1109/TICST.2015.7369403)

[3] P. Chantraket, S. Kirtsaeng, C. Detyothin, A. Nakburee and K. Mongkala, Characteristics of Hailstorm over Northern Thailand during Summer Season. Environment Asia, 2015, 8(1): 101-114.

[4] J.W. Wilson and E.A. Brandes, Radar Measurement of Rainfall - A Summary. Bulletin of the American Meteorological Society Journal, 1979, 60(9): 1048-1058.

[5] J.G. Ciach and W.F. Krajewski, On the estimation of radar rainfall error variance. Advances in Water Resources, 1999, 22: 585-595.

[6] P.W. Li, W.K. Wong, P. Cheung and H.Y. Yeung. An overview of nowcasting development, applications, and services in the Hong Kong Observatory. Journal of Meteorological Research, 2013, 28(5): 859-876.

[7] J.S. Marshall and W.K. Palmer, The distribution of raindrops with size. Journal of Meteorology, 1948, 5: 165-166.

[8] D. Rosenfeld and E. Amitai, Comparison of WPMM versus regression for evaluating Z-R relation. Journal of Applied Meteorology, 1998, 37: 1241-1249.

[9] R.A. Fulton, J.P. Breidenbach, D. Seo, D.A. Miller and T. O'Bannon, The WSR-88D Rainfall Algorithm. Weather Forecasting, 1998, 13: 377-395.

[10] P. Chantraket, P. Intaracharoen and S. Kirtsaeng, Analysis of Rainstorm Characteristics in Eastern Regions of Thailand. International Journal of Applied Sciences and Innovation, 2016, Vol.1: 58-70.

[11] M.L. Shelton, Hydroclimatology: perspectives and applications. Cambridge University, 2009.

[12] P. Chantraket, C. Detyothin, S. Pankaew and S. Boonpring, Radar rainfall estimation over the central of Thailand. Department of Royal Rain Making and Agricultural Aviation, 2013.

[13] R. Hanchoowong, U. Weesakul and S. Chumchean, Bias Correction of radar estimates based on geostatistical technique. Science Asia, 2012, 38(4): 373-385. 